\title{
Technology, translation and society
}

DOI:

10.1075/target.29.2.04olo

\section{Document Version}

Accepted author manuscript

Link to publication record in Manchester Research Explorer

\section{Citation for published version (APA):}

Olohan, M. (2017). Technology, translation and society: A constructivist, critical theory approach. Target, 29(2), 264-283. https://doi.org/10.1075/target.29.2.04olo

\section{Published in:}

Target

\section{Citing this paper}

Please note that where the full-text provided on Manchester Research Explorer is the Author Accepted Manuscript or Proof version this may differ from the final Published version. If citing, it is advised that you check and use the publisher's definitive version.

\section{General rights}

Copyright and moral rights for the publications made accessible in the Research Explorer are retained by the authors and/or other copyright owners and it is a condition of accessing publications that users recognise and abide by the legal requirements associated with these rights.

\section{Takedown policy}

If you believe that this document breaches copyright please refer to the University of Manchester's Takedown Procedures [http://man.ac.uk/04Y6Bo] or contact uml.scholarlycommunications@manchester.ac.uk providing relevant details, so we can investigate your claim.

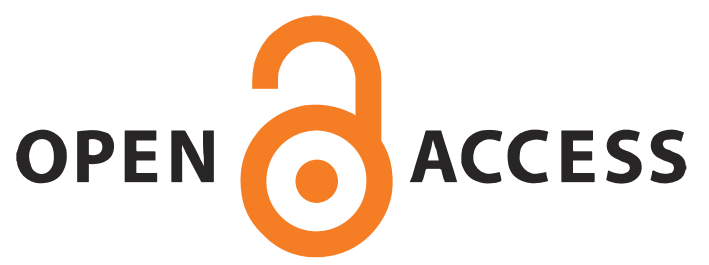




\title{
Accepted Author Manuscript
}

\author{
Olohan, Maeve (2017) 'Technology, Translation and Society: A Constructivist, \\ Critical Theory Approach', Target 29(2), special issue: Translation in Times of \\ Technocapitalism, 264-283.
}

\section{Technology, translation and society: a constructivist, critical theory approach}

\section{Maeve Olohan}

Translation studies and social theories of translation tend not to deal adequately with questions regarding the role of technology in translation and have neglected the ways in which technologies, as non-human entities, embody and materialize hegemonic and power relations. This paper seeks to address this shortcoming by looking to science and technology studies (STS) for conceptual frameworks to help us to understand and articulate a) how popular, deterministic perceptions of translation technology are perpetuated through the discourses of hegemonic actors, b) how decisions regarding design and use of translation technologies may be studied with reference to their construction and interpretation by relevant social groups, and c) how a critical theory of technology and an analytical focus on practices can help to focus our attention on the exercise of hegemonic control in the translation sector.

Keywords: translation technology; science and technology studies; social construction of technology; critical theory of technology; practice theory

\section{Introduction}

The starting point for this paper is that we still have much work to do to fully understand the ontological and epistemological bases of the impact of ideology and power on translation theory and practice. This paper, informed by schools of thought and research that converge within the discipline known as science and technology studies (STS), makes a contribution on both fronts by examining theoretical and conceptual frameworks for the social study of technology and power in translation.

STS, in the broadest sense, deals with the relationships between science, technology and society, creating "an integrative understanding of the origins, dynamics, and consequences of science and technology" (Hackett et al. 2008, 1). STS is an interdisciplinary field made up of a variety of approaches, with both commonalities and incompatibilities, often challenging conventional ideas from the disciplines of sociology, history and philosophy of science. One of STS's underlying assumptions is that science and technology are social and rhetorical activities; this discipline studies the construction of knowledge and artefacts, including the role of the material world in these processes of construction (Sismondo 2010, 11). As Sismondo $(2010,71)$ notes in his accessible introduction to the field, something on which most STS scholars agree is the co-construction of scientific and social worlds. 
This paper, in keeping with the aims of the special issue, is predominantly conceptual. It examines STS conceptualisations of technology that can contribute to the study of translation technology, thus potentially enriching existing translation studies frameworks that provide little or no reflection on translation technology and its social and ideological roles. Without producing a reductionist and simplistic account of decades of STS scholarship, the aim is to focus on some key conceptual strands that could offer translation scholars productive avenues of enquiry for thinking about the complex relationships between technology, translation and society.

The paper begins by exploring the concept of technological determinism generally and in relation to translation technology. A challenge to determinism is then advanced through social constructivism of technology. Both sections prompt a series of questions regarding translation technologies that can guide new research in this field. Recognition of some limitations of constructivist approaches then leads to consideration of a critical theory of technology that adds a macro-analytical dimension capable of accommodating issues of power and ideology.

\section{Technological determinism}

Technological determinism combines two assumptions. The first is that technological developments take place independent of social, economic or political forces (Wyatt 2008, 168). Technologies are assumed to develop autonomously, following an internal functional logic (Feenberg 1992, 304; Bijker 2010, 71; Dafoe 2015, 1048). A consequence of this deterministic assumption is that we do not consider that choices are made in the development of technologies, ignoring what those choices are, who makes them and to what ends.

The second aspect of technological determinism relates to the assumed impact of technology on society, i.e. that technologies determine social events or societal development. In other words, "technological changes force social adaptations, and consequently constrain the trajectories of history" (Sismondo 2010, 96), as reflected in our labels for historical periods: stone age, bronze age, digital age, and so on. This also entails a view of technological progress as teleological and unilinear, following a sequence of necessary stages always proceeding from less advanced to more advanced configurations. A consequence of this assumption is that we do not take responsibility for technological choices we make as users, but rather perceive technological development as having an inevitable, unstoppable momentum, with predictable outcomes. This goes hand in hand with a common perception of 'progress' or improvement in the human condition as being attainable (only) through technological developments which tend to be perceived as morally neutral.

A deterministic conception of technology has clear parallels with the Western tradition of positivist views of science as rational, objective, culturally neutral and value-free. However, STS scholarship, particularly since the 1960s, has challenged those conceptualisations. Laying bare the cultural, political and socioeconomic shaping of scientific knowledge and practice and technological development, STS has offered constructivist understandings of science and technology, focusing, for example, on how science and culture are co-constitutive and how science is intrinsically value-laden (Longino 1990; Haraway 1991; Harding 1998; Harding 2011). Similarly, constructivist approaches to technology, as discussed further in the next section, argue that technologies do not have essential 
features in and of themselves nor just one potential use. They claim that technological development is not unilinear, but can proceed in many directions; there may be several workable solutions to any problem and social actors make a choice among the various technically viable options. Thus, while a strongly deterministic view of technology seems to absolve both technology developers and users of responsibility for the technologies they develop and use, a constructivist and less deterministic view focuses attention on the reciprocal shaping of technologies and societies through the more complex relationships that intertwine them.

Despite post-positivist challenges to determinism, a deterministic model of technology seems to chime with many people's everyday experiences and perceptions; that is to say, we tend to know very little about where our technologies come from, how or why they were designed or how they work (Wyatt 2008, 169). We simply adapt ourselves to their requirements and we hope they will work as expected or promised; the deterministic explanation therefore seems to be the 'common sense' explanation for many of us (ibid.). We are, for example, accustomed to organisational change or institutional restructuring being justified in technologically deterministic ways. Public discourses and accounts of developments in information and communications technology (ICT) often associate technological progress with improvements in conditions or quality of life. The impression is produced that technological trends follow an internal logic and have a level of autonomy or a "technological momentum" (Hughes 1983).

Winner $(2001,14)$ notes how those who work in ICT also tend to embrace the perception that we are "swept along by a law-driven process of technological change". As an example of this, he quotes Moore's law, a prediction first made in the 1960s by the founder of Intel according to which the processing power of computers would double every two years (Moore 1975). This exponential trend seems to have held for the past fifty years for chips in integrated circuits and for longer if other computing technologies are considered, and it leads to perceptions that such technological advances dominate our lives and force us to keep up.

However, some recent reports make it clear that, rather than being subjected to technological inevitability, the industry has explicitly set out to ensure that its R\&D activities reproduce that trend, with vast budgets allocated to that end (Dorrier 2016). Waldrop (2016) explains how, since the 1990s, the semi-conductor industry has biennially devised a research and development strategy (dubbed "More Moore") to keep the industry firmly on this exponential track, so that Moore's law functions as a self-fulfilling prophesy. For the first time in March 2016, however, the R\&D roadmap is not centred on Moore's law but on other innovations, since it is materially too difficult to continue to increase the transistor count in chips. Yet this will not prevent the technology corporations from continuing to perpetuate an alternative interpretation of Moore's law in the interest of selling new devices. By re-interpreting the law for consumers as "user value doubles every two years", the corporations intend to add functionality to new devices to perpetuate this notion of unassailable technological progress (Waldrop ibid.).

In the light of the "visions of run-away technology that prevail in society at large", Winner (2001, 15) criticises STS for being too inward looking and not noticing the discontinuity between STS theories of technology and those commonly held perceptions. However, he explains the latter not as strong determinism but as what he has called "technological somnambulism", i.e. our lack of awareness of our technological choices. In a seminal 1983 contribution Winner urges us to resist our 
technological somnambulism and ask questions about what kind of world we are making as we create and use technologies, rather than "sleepwalk[ing] through the process of reconstituting the conditions of human existence" $(1983 / 1986,10)$.

Much of the discourse produced within the commercial translation sector, as in other spheres of public discourse, appears to reflect technologically deterministic stances to varying degrees. A blog entry by Lionbridge, a leading localisation company, for example, notes how new globalization solutions are needed because content is no longer only text-based but delivered and shared through a range of media. Lionbridge puts the onus on the language services sector to adjust their current practices to meet this demand and urges language service providers (LSPs) to innovate and adapt their methods "to suit the constantly changing world of technology" (Donoghue 2013). Similarly, a recent blog entry by TAUS, an organisation offering resources and support for translation automation, encourages us to imagine

a machine that can translate across a hundred languages and do that real-time. The quality and accuracy of these machine translations may not always be perfect, but it is so convenient that we learn to live with it, adjust ourselves and tweak the machine where we can. (van der Meer 2016)

Wyatt $(2008,172)$ cautions social researchers against dismissing the technologically determinist views that are held by groups of people they study. Rather, she urges scholars to seek to understand how and why people are committed to determinism and how the view continues to hold sway. A systematic study of practices enacted in the translation sector and discourses produced about professional translation and technology would serve to reveal whether (or the ways in which) translation and translation practices are perceived as being driven by technological factors, giving insights into the extent of technological determinism or somnambulism both reflected in and constructed by those practices and discursive choices.

The sense that the adoption of certain technologies has an obligatory character (Chandler 2012) also appears to pervade discourses produced by translators and LSP representatives and merits investigation. The root of this perception may be in the competitive nature of the sector and the precarity of work; technologies such as translation memories or machine translation are often constructed as offering an extension of human capabilities, which, in turn, is construed as bringing an increase in productivity and a competitive advantage to the translator and/or to the LSP.

A mechanism related to obligatory technologies is dependency (Chandler 2012). The trend, prevalent in modern society, to define problems in technological terms, or in terms of technological fixes, and to deem technological fixes as superior to other forms of fixes, is one form of dependency, reflected in the Internet-centrism and solutionism discussed by Morozov (2013). Morozov borrows the term 'solutionism' from architecture, where Dobbins (2009) had introduced it in the context of city design and planning; while problem-driven design tries to understand and take due account of the social, cultural, spatial and other complexities of a particular planning situation, 'solution-driven design' tends to look for a 'magic bullet' solution, "reaching for the answer before the questions have been fully asked" (Dobbins 2009, 182). By analogy, Morozov conceptualises the technological solutionist ideology that tackles complex social issues as neatly defined problems for which there are convenient computational solutions, or as transparent processes which can be easily optimised through more efficient technologies. Morozov, through discussion of numerous examples, highlights the dangers 
of solutionism, not only in underestimating, misunderstanding or simplifying problems when applying quick fixes but also in treating various apparent inefficiencies and ambiguities as problems to be resolved when, in fact, they may be "virtues in disguise" (Morozov 2013, 6).

Morozov argues that Internet-centrism and solutionism go hand in hand. Used as a shorthand for a wide range of technologies, 'the Internet' is regarded by Internet-centrists, especially optimists, as a fixed and unified entity that is all-powerful and that facilitates the solutionists' quest for technological fixes (Morozov 2013, 22). Moreover, various technologies tend to be subsumed into the grand narrative of 'the Internet', in the process losing their autonomy and historical background (Morozov 2013, 18). Both solutionism and Internet-centrism are dependencies that may have some relevance in the case of translation technologies and translators. The most widespread form of dependency, as discussed by Chandler (2012) is when the adaptations to social practice are such that it is difficult to perform those practices without the technology; communication technologies, the internet, term bases and translation memory are likely to fall into this category for many translators. In all such cases, the use of the technology is not obligatory, strictly speaking, but the cost of not using it is extremely high.

Key questions for translation studies to address, therefore, are whether and how actors in the translation sector hold technologically deterministic views, and how those views relate to ideological, institutional and political perspectives. What are the potential causes and consequences of those deterministic views? Is it commonplace for translators or LSPs to perceive the introduction and use of certain technologies in their workplace as an inevitable consequence of some perception of technological progress that arises from functional possibilities of the technology? Is the use of certain technologies perceived as obligatory by translators and by LSPs? On what basis are these judgements of obligation formed? Are technologies or technological changes perceived as forcing changes in the social practices of translation? When actors offer justifications for the social order of the translation profession, are they based around technological factors? What can we learn about the links between translation and technology, by studying translation practices, lived experiences and discourses? What have been the paradigms dominating those discourses? Have they been contested? If so, how?

Much of this questioning points us towards a particularly pertinent overarching question in the framework of this special issue, namely what are the hegemonies reflected in the discourses and applications of translation technologies? As discussed by Fisher (2010: 232) following Habermas and others, both technology and technology discourse can be regarded as major sources of public power in our societies. Hegemony is used here in the sense offered by Gramsci (1971) to designate a form of control exercised, not through coercion (domination) in labour relations but achieved through relations of consent and legitimation. The next sections explore constructivist and critical-theoretical perspectives on technology that can offer conceptual frameworks for considering the hegemonies embodied in the design, promotion and use of translation technologies.

\section{Social construction of technology}

Constructivist approaches to technology represent a direct challenge to and criticism of technological determinism as outlined above. An approach known as Social Construction of Technology (SCOT) is one of the best known and most widely applied. SCOT developed from a workshop and a resulting volume of papers entitled The Social Construction of Technological Systems (Bijker, Hughes, and Pinch 1987), marking the start of the MIT Press Inside Technology series, still active today. A 
previously published paper by SCOT founders (Pinch and Bijker 1984) had paved the way, and the longevity and significance of the ideas of the 1987 volume were marked by an anniversary edition 25 years later (Bijker, Hughes, and Pinch 2012).

SCOT, like all STS research, is concerned with the entanglements of technology and society. It takes a non-essentialist view of technology and its contexts, and it produces non-deterministic (indeed antideterministic) accounts about the social processes through which actors and social groups engage with technologies. A basic tenet of the SCOT research agenda might be summed up by the following statement:

One should never take the meaning of a technical artifact or technological system as residing in the technology itself. Instead one must study how technologies are shaped and acquire their meanings in the heterogeneity of social interactions. (Bijker 1995, 6)

According to Bijker (1995, 13), a theory of technological development needs, firstly, to facilitate the analysis of both technological change and technological stability and continuity. Secondly, it needs to consider the 'working' of an artefact as something to be explained in the context of its sociotechnical development, rather than as being the reason for the development. Thirdly, the conceptual framework should allow for an analysis of structurally constrained aspects of technical change as well as actor-oriented and contingent aspects. Fourthly, it should not make a priori distinctions between the social, technical, scientific and political. Bijker $(1995,16)$ puts forward a descriptive model to create a set of case studies that can be compared and combined analytically to develop generalisations.

One of the best known case studies illustrating the SCOT approach is Bijker's study of the development of the bicycle. As outlined in Pinch and Bijker (1984) and elaborated in Bijker (1995), the bicycle started as a set of at least two distinct designs; this is, different technologies with some shared elements but designed to meet different needs (one was more concerned with safety while another was more interested in generating speed). One design won out and became accepted, but others co-existed for a time. Looking back on its development, we might be tempted to see the now extinct designs as clumsy and unsuccessful stages in the development of the design that prevailed. However, Pinch and Bijker (1984) argue for another view, which is that the designs were alternatives to one another, addressing different problems for different users, and that it would not be correct to project the technical logic of the finished object back into the past as a cause of development.

The unit of analysis for SCOT research can be the technological artefact, as in the bicycle example, but it can also be a technological system (as in Hughes' [1983] well-known work on the history of electrification infrastructures) or a sociotechnical ensemble in which the social and technical are bundled together and mutually constructed (Bijker 1995, 273), or a combination of these, depending on the research question (Bijker 2010, 66). Hommels' (2005) study of cities serves as an example of the analysis of sociotechnical ensembles of humans, infrastructures, buildings, political structures and values.

Bijker's (1995) SCOT analysis requires the researcher to identify "relevant social groups" and their descriptions of the technological artefact, i.e. the explicit meanings they attribute to it. Different relevant social groups produce different descriptions and different artefacts, as in the case of the different bicycle designs (Bijker 2010, 68). These different meanings, indicative of the "interpretive 
flexibility" of the artefact, are studied and deconstructed by the researcher, who traces how the interpretive flexibility diminishes because some artefacts gain dominance over others and meanings converge. As one artefact emerges from this process of social construction (Bijker 2010, 68), the process has undergone "closure" and a "stabilization" of the meaning of the artefact, i.e. one type of bicycle became dominant and the others became obsolete. In a third analytical step, the processes of construction and stabilisation are analysed and explained by interpreting them in the context of the relevant social groups' technological frames, including their understanding of a technology and the ways in which it is conditioned by their knowledge, practices, values, shared meanings, other existing technologies, etc. The technological frame structures the interaction between members of the social group and constrains their freedom of choice in designing new technologies. The concept of technological frame, therefore, also encourages us to attend to the constraints arising from existing technological systems (Bijker 1995, 264).

SCOT offers a set of sensitising concepts or a heuristic framework for the study of sociotechnical change (Bijker 1995, 49). In their preface to the 2012 anniversary edition, Bijker and Pinch (2012, xxiii) note that it is difficult to think of a technology that has not been studied from a SCOT perspective over the past 25 years, and impossible to think of a technology that cannot be studied in that way. However, translation technologies are one area that has remained untouched by SCOT. Some recent contributions by translation scholars (Olohan 2011, Kenny 2011, Cronin 2013, Kenny and Doherty 2014, O'Hagan 2016, Littau 2016) mark the beginnings of critical studies of translation technology and materiality, but there is much untapped SCOT-inspired potential, whether we focus on material objects or artefacts (for example a piece of translation memory software), a practice (for example post-editing machine translation), or knowledge (for example the knowing enacted in the practice of using a translation project management system).

By way of example, we might think of existing historical accounts of machine translation (MT) (e.g. Hutchins 1995). Such accounts tend to outline the basic technical principles of MT and document the shift from the rule-based approach to the statistics-based systems that now dominate. Reference is usually made to some of the institutions which were key in developing the technologies (e.g. university departments or research departments within international corporations) and the narrative may include some discussion of military applications and of national or international bodies and their decisions at significant moments (e.g. withdrawal of US government funding after the ALPAC report of 1966, or funding of the Eurotra project by the European Commission during the 1980s). However, there are no accounts that set out to consider MT as a social product and seek to account more fully for the interplay of social, technical, cultural, economic and ideological factors through those periods of sociotechnical change.

Similarly, other translation technologies, e.g. translation memory software, translation project management systems or localisation tools, have not been given this kind of analytical treatment as yet, whether in a historical account of their design and development or in analyses of present-day implementation and use. Where and how are the decisions pertaining to the design of translation technologies made, and by whom? Which actors or which social groups are relevant? Are actors aware of and can they identify other relevant actors? In studying the design of translation technology artefacts, for instance, the software developers of companies such as SDL, Kilgray and Star, to name but a few, could constitute relevant social groups. Does their ownership of resources give them dominance in the design process? What are the differences in design processes between companies 
like SDL and Star, who are both technology developers and providers of translation services, and those who are purely software developers, like Kilgray or MemSource? Are there competing interests in the development of the technology? What is the involvement of users (not just translators, but also translation companies and their clients) in design processes? To what extent can our analyses consider clients, not as direct users but as people to whom services are provided using the technology? Is the decision-making of designers exposed for other actors to heed, or is it concealed behind an illusion of technological obligation or necessity?

Given that statistical machine translation (SMT) and neural machine translation engines are relatively new products in the commercial market, a study of the interpretive flexibility of machine translation technologies and the ongoing process towards stabilisation of meanings would be of particular interest. The widespread public use of MT technologies and the hegemonic position occupied by Google also makes MT a relevant case for study in a sociotechnical, SCOT framework.

The constructivist approach is interested in the different ways in which social groups use and interpret technologies, but also how they change and affect the technical artefact over time. It would be important to not only address the impact of technologies on translation, but also the interaction between technologies and translators (Olohan 2011, O'Brien 2012). Thus, to what extent do users of translation technologies contribute to technological change, by adapting software to their needs? To what extent and how do they feed back into the design process?

As noted above, the success of a technology is not a function of specific features of the technology but rather is related to the take-up by relevant social groups. Thus, in relation to a particular translation technology we might ask who takes it up and promotes it. What is the size and strength of that group? What claims does a dominant social group make for a technology that enables it to outdo the competing claims made by other groups? These questions focus attention on rhetorical and discursive choices of technology developers, but also on others who may define users of the technology, create particular professional associations for the technology or depict it as solving particular problems. In the context of professional translation, our analytical attention may therefore be directed at the discourses of translators and LSPs, but also professional translator associations, associations of translation companies and other formalised groups of users or developers, think tanks, and market research companies. This analysis would also raise questions of who claims to speak for whom within the sector, which voices are loudest and which go largely unheard. In addition, the relevant social groups can include technology trainers and translation researchers, whose links with translation technology companies are likely to play significant roles in the later take-up of particular technologies by their students as they enter the labour market.

Many of these questions might be fruitfully addressed by relatively micro-analytical approaches to decision-making or technological implementation in the workplace. We lack such studies focusing on social construction in the design of translation technologies, and research on how translators and others use technologies in constructivist terms. Likewise, we have few insights into how technology shapes and is shaped by translation practices (Olohan 2011) or how an LSP or other organisation in the translation sector adapts to a translation-related technology. Thus, there is no doubt that SCOT case studies could make a valuable contribution to translation studies by contextualising the design, development and implementation of translation technology with a focus on the perceived meanings and purposes of the technologies among various social groups. 
Notwithstanding its widespread application elsewhere, there are also clear limitations to this form of SCOT analysis. Critics note the difficulty of working with the concepts of relevant social groups and dominant technological frames, not least because they have to be identified by the researcher and important groups may be missed (Wyatt 2008, 170). Moreover, as Klein and Kleinman (2002) point out, SCOT analyses run the risk of assuming that all groups are equal and not adequately recognising power asymmetries. Where analyses focus on political power struggles between social groups, as in Bijker's (1995) account of the introduction of fluorescent lighting in the US in the 1930s, the SCOT approach shows how technology was embedded in the political power struggles but also shaped by them; the power relations were thus constituted and materialised in the version of the technology that was eventually introduced. However, analyses are typically more focused on the strategies used by groups to achieve a certain technological outcome than on analysing the source and nature of power, power inequalities or the ways in which it is exercised. This limitation is also noted by Leonardi and Barley (2010), who offer several possible explanations for it. The most pertinent one in this context is that, in focusing on local interactions and negotiations of meaning, scholars attend to microinstitutions but neglect the macro-institutions, such as relations of production and distributions of power (Leonardi and Barley 2010, 38). The next section, therefore, looks at ways in which notions of power may be productively integrated into SCOT analyses of translation technologies.

\section{Technology and power}

As seen above, a clear consequence of thinking less deterministically is that the social role of technology needs to be studied and interpreted within its social context. SCOT analyses go some way to sensitising us to the non-essential nature of technology, and the intervening of social groups in the design and implementation of technologies. Yet, critics have also noted the tendency for the SCOT pendulum to have swung so far in the anti-deterministic direction that it neglects certain key questions about the effects of technology (Dafoe 2015, Leonardi and Barley 2010). It is certainly the case that technological determinism, particularly in its strongest form, has been so frequently and vehemently discredited by STS researchers that it is now predominantly a term of criticism (Lynch 2008, 10; Dafoe 2015, 1049). However, Dafoe points to various instances of unintended consequences of technological choices or decisions and argues that how strongly technologies shape social relations and how foreseeable the consequences of technology are should be seen as a matter of degree (ibid. 1054). He believes that there are contexts in which humans do indeed have relatively little control over sociotechnical choices; he uses the concept of "military-economic competition" to explain those situations and the concomitant pressures they exert. His approach prompts him to ask questions, on the one hand, about the ways in which particular kinds of technology are more autonomous and powerful in shaping society, and on the other hand, about ways in which particular groups of people shape their sociotechnical systems (Dafoe 2015, 1050).

Against the backdrop of SCOT accounts that have often stopped short of tackling issues of ideology and power in the development and use of technology at macro levels, Andrew Feenberg (1992; 1999; 2005) adds a very useful analytical layer by considering more explicitly the power structures and struggles in which technology is implicated. Influenced by Marx, Heidegger and Marcuse among others, as well as the constructivism of STS, Feenberg's critical theory of technology emerges from a body of philosophical work that challenged conceptions of technology as neutrally utilitarian. From his starting point that "technology can be and is configured in such a way as to reproduce the rule of 
the few over the many" (Feenberg 2005, 48), he sets out to integrate the constructivist methodological insights into a theory of modernity, with due recognition of how the principal form of power in our technologically oriented societies is technological power (ibid., 50).

As discussed in the previous section, social groups influence the design of technologies. Feenberg introduces the notion of 'technical code' to describe "the realisation of an interest or ideology in a technically coherent solution to a problem" (ibid., 52). It is the technical code that determines which of a range of technically feasible options are chosen to fulfil a specific social goal. Technical codes thus inscribe hegemonic values. This is aptly illustrated by Feenberg $(1992,310)$ using the example of the factory assembly line. While often depicted as technological progress, the assembly line was a technology designed to achieve management goals, i.e. the increase of productivity and profits through de-skilling labour and increasing management control by pacing work. It can therefore be perceived as technical progress only in the specific social and cultural contexts of a Fordist organisation of the labour process. It would not be considered as technical progress, for example, in a workers' cooperative, where labour discipline may be self-imposed rather than imposed from above, and where an increase in productivity might be sought or achieved through rather different means and technology.

The assembly line example illustrates how the design of technologies reflects prevailing ideologies. The institutions with the power to select certain technologies choose from among many possible technological configurations and they do so to incorporate them into their theoretical or functional systems, thus validating and reproducing the prevailing systems. The dominant hegemony therefore reproduces the system, obscures the act of choosing, and projects "a deterministic image of a technically justified social order" (Feenberg 1992, 310). In modern society, this power is exercised by owners of businesses or their representatives, who "reproduce the conditions of their own supremacy at each iteration of the technologies they command" (Feenberg 2005: 53). This form of technological hegemony entails a "form of domination so deeply rooted in social life that it seems natural to those it dominates" (Feenberg 1992, 309). This form of control chimes both with Gramsci's (1971) notion of hegemony and Lukes' third dimension of power, or "power by domination" (2005), whereby the powerful exert control over the dominated, without coercion, through a pervasive ideology. Similarly, Hornborg (2014) argues that modern power relations are based on economic and technological accumulation, and that people are controlled by social elites who extract labour and compliance through claims and promises of continued technological and economic growth. Their discourses are successful because of the cultural assumption that material objects are "politically innocent and immune to moral critique" (Hornborg 2014, 133).

However, recognising how hegemonic values are inscribed in technological choices is not to claim that technology per se is neutral; instead, Feenberg argues, "there is no such thing as technology as such", since the technology that comes into existence already "favours specific ends and obstructs others" (Feenberg 2005: 54). Rather, a critique of technology needs to examine the cultural-political horizon under which the technology was designed, dispelling the "illusion of technical necessity", thereby revealing the relativity of the technical choices (1992, 311). As summarised by Thorpe (2008, 72 ), this critical theory of technology aims "both to expose dominatory values and to suggest the possibility of inscribing new values in technological design". 
With the worlds of translation and translation technology dominated by a small number of global players and recent years characterised by a flurry of mergers and acquisitions, critical studies of translation technology need to focus on the power struggles to develop, acquire or maintain certain technologies and the strategies used to shape technological outcomes. To what extent is market dominance related to claims made for the technology, sheer spending power or other forms of ideological inculcation?

Translation and technology development companies operate within a system of global capitalism which, much like the capitalist systems discussed by Marx and Gramsci, is distinguished by control of the conditions of labour to produce profit. As was the case with the Fordist assembly lines in factories, technology continues to be designed, implemented and employed in ways that are aimed to achieve those goals of control of labour and reduction of costs. With the increasing tendency to outsource work to freelancers, the translation sector might well be described as a post-Fordist flexible regime (Robinson 2012, 354) in which labour is reduced to an economic input, required to be flexible so that it can be mobilised or dispensed with as required. Robinson argues that the maximisation of profits through cost reductions is facilitated in such regimes by globalising "third-wave technologies" of ICT and the internet, among others $(2004,21)$. For the specific case of the translation sector, we might add translation technologies to the list, in particular in their networked or cloud-based forms, which produce a misleading impression of autonomy by 'allowing' translators the 'freedom' to complete their work anytime, anywhere, while their lived experience may be that of a translator on call, asked to complete translations any time of the day or night to be published as part of continuous updates of global content on globally accessible websites.

As noted, a common aspect of the capitalist workplace is that technology is frequently deployed by company owners or managers to reduce costs and control labour which, in turn, result in the deskilling of workers. However, some scholars (e.g. Adler 2007) offer alternative, if controversial, views of the impact of capitalism on skills development, e.g. that for a minority of workers their skills are upgraded while others are de-skilled, or even the view that capitalism brings a long-term development of skills among workers. Adler argues the latter point by defining skills as being related to, firstly, 'the technical content of workers' tasks - their relationship to the objects of their work and to the tools they use" $(2007,1316)$ and, secondly, "the worker's mastery of the associated social relations" (ibid., 1318), where these encompass relations within a work unit, horizontal relations across units and vertical authority relations. He claims that today's workers tend to be more interdependent (and less autonomous), and thus require greater mastery of social relations, and that the technical content of their tasks has also generally increased, thus constituting a development of workers' skills.

This is an interesting question to consider from the perspective of translators and translation technologies. On the one hand, translators' activities seem likely to shift toward post-editing MT output, and this can be seen as a de-skilling move. On the other hand, translators also seem likely to continue to be commissioned to translate content that is described as 'creative' or that plays a significant function in external relations while also being expected to manage and understand MT systems, post-editing processes and techniques. They may also have involvement in MT engine training, tuning or evaluation (Kenny and Doherty 2014). Thus, these skills are added to the existing competence requirements in linguistic, cultural, subject-specific, professional, interpersonal and technical domains. In line with those technological developments, translators also engage 
increasingly with ethical and legal issues around data management and security, intellectual property rights, and other complex matters. Thus, at least in the foreseeable future, it seems appropriate to think about the increasing use of technology as being frequently accompanied by an upskilling of translators, which is reflected in the need for translators to receive specific postgraduate training and education.

What is a more pressing issue for the translation sector is not de-skilling but the undervaluing of translators' skills and outputs. To understand this phenomenon requires us to grasp also the ways in which, through their consent to the hegemonic capitalist relations of production and the way in which freelance working is organised, translators have themselves become "invested in the production of surplus as a function of [their] own fulfilment" (Herman 1982, 15). As freelancers they consent to work towards securing limited surplus value for themselves while in fact they are also securing greater surplus value for the LSP. The LSP, in turn, obscures that surplus value from them by generally not divulging the rates being charged to clients for the work of the translators. The use of translation technology can exacerbate that situation further, as LSPs use technologies to justify the payment of lower rates for work with translation memories and machine translation outputs.

In addition to such questions about the organisation and control of labour and relations of production in LSPs, many of the questions outlined in the previous sections can also be revisited in the light of a critical theory of technology, prompting us to probe more deeply into the organisations that dominate the sector and influence others to follow their practices, leading to a high degree of homogenization of technology use. Our scholarship would benefit from an understanding of how power is exerted by a small but dominant set of technology developers but also by other players, like TAUS, whose mission is to promote language technology; there is, for example, no consideration thus far of how such organisations or market research consultancies, like Common Sense Advisory, influence the sector and its agents by promulgating and privileging certain perspectives or values. Similar questions may be asked in relation to the organisations that represent the translation companies and the professional associations that represent translators. Only through study of the discursive choices and practices of the full range of actors, including the dominant ones, are we likely to gain a deeper understanding of such power dynamics, particularly given the hegemonic (and thus hidden) nature of the control exerted. This analysis must include consideration of the economics of translation as constructed within the current system of global capitalism, a subject which, unfortunately, has attracted the attention of few translation scholars to date (see, for example, Cronin 2003, Baumgarten 2016). By contrast, translation scholars have devoted attention to acts of activism and resistance by translators and interpreters, but seldom in the settings in which most translators are to be found, namely in the distributed workplaces of the globally constituted commercial translation sector. As Harvey (2015) notes, it is difficult to organise resistance in present-day workplaces due to the deterritorialised nature of labour. The possibilities and challenges of resistance in the workplace, in the face of the technologically embodied hegemonies outlined here, is beyond the scope of this paper but could offer a productive starting point for further development of these ideas.

Practice-theoretical studies of translation, technology design and related practices may provide a fruitful way to bring together issues of technology, translation and power. Building on seminal work by Wittgenstein, Bourdieu and Giddens, among others, the second generation of practice philosophers and sociologists, notably Schatzki (1996) and Reckwitz (2002), theorise practice as "a temporally unfolding and spatially dispersed nexus of doings and sayings" (Schatzki 1996, 89). They provide a 
foundation for an expanding body of research on everyday and workplace practices (e.g. Shove, Pantzar, and Watson 2012; Bräuchler and Postill 2010; Nicolini 2012; Warde 2016). Notwithstanding some variation in terminology, the social is seen as a field of interconnected practices, understood as "embodied, materially mediated arrays of human activity centrally organised around shared practical understanding" (Schatzki 2001, 2).

In addition to asking why and how people do what they do, practice scholars may seek to understand how practices endure and change, and how they produce and reproduce social order. This can be accomplished through a process of "zooming in" (Nicolini 2009, 1391) on the discursive and material accomplishment of practices, and then "zooming out" (ibid.) to the connections between practices as they constitute the landscape of life. Thus, in professional work settings, in addition to shedding light on embodied and materially mediated practices of translation and knowing (Olohan forthcoming), practice analysis may be combined with critical theoretical approaches to technology and hegemony, as outlined here, to examine how capitalist organisation and work relations are produced and reproduced in and through historically, culturally and materially embedded practices. Useful illustrations of this approach, on which future studies of translation could be modelled, include Contu and Willmott's (2006) critical theoretical reading of Orr's (1996) study of photocopy technicians, and Contu's (2014) more recent analysis of power relations enacted in and through work practices in a digital media agency. In those cases Laclau and Mouffe's (1985) theory of social hegemony provides a conceptual framework for understanding organisational and capitalist power relations and dynamics.

\section{Conclusion}

Technology is an integral part of translation practice in the world. Not taking technology into consideration in our theoretical models and frameworks means we have, at best, a partial understanding of how translation works. The frameworks introduced in this paper offer us an ontological sensitivity with which to approach the study of translation and technology, and an interpretive space for considering translation technology in relation to notions of hegemony and power asymmetry. Through these and other insights, translation studies can expand its repertoire of applicable social theories to account for the hitherto rather neglected technological and material dimensions, to understand the nature of technological development and articulate how technology embodies and materializes the hegemonies and power relations of the translation sector.

\section{References}

Adler, Paul S. 2007. "The Future of Critical Management Studies: A Paleo-Marxist Critique of Labour Process Theory." Organization Studies 28 (9): 1313-45.

Baumgarten, Stefan. 2016. "The Crooked Timber of Self-reflexivity: Translation and Ideology in the End Times." Perspectives 24 (1): 115-129.

Bijker, Wiebe E. 1995. Of Bicycles, Bakelites, and Bulbs: Towards a Theory of Sociotechnical Change. Cambridge, MA: The MIT Press.

2010. "How Is Technology Made? That Is the Question!" Cambridge Journal of Economics

34 (1): 63-76. 
Bijker, Wiebe E., Thomas P. Hughes, and Trevor Pinch, eds. 1987. The Social Construction of Technological Systems: New Directions in the Sociology and History of Technology. Cambridge, MA: The MIT Press.

, eds. 2012. The Social Construction of Technological Systems: New Directions in the Sociology and History of Technology. 2nd ed. Cambridge, MA: The MIT Press.

Bijker, Wiebe E., and Trevor Pinch. 2012. "Preface to the Anniversary Edition." In The Social Construction of Technological Systems, ed. by Wiebe E. Bijker, Thomas P. Hughes, and Trevor Pinch, 2nd ed., xi-xxxiv. Cambridge, MA: The MIT Press.

Bräuchler, Birgit, and John Postill, eds. 2010. Theorising Media and Practice. New York: Berghahn Books.

Chandler, Jennifer A. 2012. “'Obligatory Technologies': Explaining Why People Feel Compelled to Use Certain Technologies.” Bulletin of Science, Technology \& Society 32 (4): 255-64.

Contu, Alessia. 2014. "On Boundaries and Difference: Communities of Practice and Power Relations in Creative Work." Management Learning 45 (3): 289-316.

Contu, Alessia, and Hugh Willmott. 2006. "Studying Practice: Situating Talking About Machines." Organization Studies 27 (12): 1769-82.

Cronin, Michael. 2003. Translation and Globalization. London: Routledge. 2013. Translation in the Digital Age. London: Routledge.

Dafoe, Allan. 2015. "On Technological Determinism: A Typology, Scope Conditions, and a Mechanism." Science, Technology \& Human Values 40 (6): 1047-76.

Dobbins, Michael. 2009. Urban Design and People. Hoboken, NJ: John Wiley.

Donoghue, Patrick. 2013. "Common Sense Advisory Lists Lionbridge as the \#1 Language Service Provider." Accessed June $\quad 2016$. http://blog.lionbridge.com/translation/2013/06/07/common-sense-advisory-says-lionbridgeis-1-language-service-provider/

Dorrier, Jason. 2016. "Will the End of Moore's Law Halt Computing's Exponential Rise?" Singularity HUB. Accessed March 8, 2016. http://singularityhub.com/2016/03/08/will-theend-of-moores-law-halt-computings-exponential-rise/

Feenberg, Andrew. 1992. "Subversive Rationalization: Technology, Power, and Democracy." Inquiry 35 (3-4): 301-22.

1999. Questioning Technology. London: Routledge.

. 2005. "Critical Theory of Technology: An Overview." Tailoring Biotechnologies 1 (1): 4764.

Fisher, Eran. 2010. "Contemporary Technology Discourse and the Legitimation of Capitalism." European Journal of Social Theory 13 (2): 229-252.

Gramsci, Antonio. 1971. Selections from the Prison Notebooks of Antonio Gramsci, edited and translated by Quintin Hoare and Geoffrey Nowell Smith. London: Lawrence and Wishart.

Hackett, Edward J., Olga Amsterdamska, Michael Lynch, and Judy Wajcman. 2008. "Introduction." In The Handbook of Science and Technology Studies, ed. by Edward J. Hackett, Olga Amsterdamska, Michael Lynch, and Judy Wajcman, 3rd ed., 1-7. Cambridge, MA: The MIT Press.

Haraway, Donna. 1991. Simians, Cyborgs, and Women: The Reinvention of Nature. London: Routledge.

Harding, Sandra. 1998. Is Science Multicultural? Postcolonialisms, Feminisms, and Epistemologies. Bloomington, IN: Indiana University Press. 
ed. 2011. The Postcolonial Science and Technology Studies Reader. Durham, NC: Duke University Press.

Harvey, David. 2015. “Consolidating Power.” ROAR Magazine. Accessed September 3, 2016. https://roarmag.org/magazine/david-harvey-consolidating-power/.

Herman, Andrew. 1982. "Conceptualizing Control: Domination and Hegemony in the Capitalist Labor Process." The Insurgent Sociologist 11 (3): 7-22.

Hommels, Anique. 2005. "Studying Obduracy in the City: Toward a Productive Fusion between Technology Studies and Urban Studies.” Science, Technology \& Human Values 30 (3): 32351.

Hornborg, Alf. 2014. "Technology as Fetish: Marx, Latour, and the Cultural Foundations of Capitalism." Theory, Culture \& Society 31 (4): 119-40.

Hughes, Thomas P. 1983. Networks of Power: Electrification in Western Society, 1880-1930. Baltimore: John Hopkins University Press.

Hutchins, W. John. 1995. "Machine Translation: A Brief History." In Concise History of the Language Sciences: From the Sumerians to the Cognitivists, ed. by E. F. K. Koerner, and R. E. Asher, 431-45. Kidlington: Elsevier.

Kenny, Dorothy. 2011. "The Ethics of Machine Translation." In Proceedings of the 20 ${ }^{\text {th }}$ NZSTI National Conference. Reflections on Language and Technology, ed. by Sybille Ferner. Auckland: New Zealand Society of Translators and Interpreters.

Kenny, Dorothy, and Stephen Doherty. 2014. "Statistical Machine Translation in the Translation Curriculum: Overcoming Obstacles and Empowering Translators." The Interpreter and Translator Trainer 8 (2): 276-94.

Klein, Hans K., and Daniel Lee Kleinman. 2002. "The Social Construction of Technology: Structural Considerations." Science, Technology \& Human Values 27 (1): 28-52.

Laclau, Ernesto, and Chantal Mouffe. 1985. Hegemony and Socialist Strategy: Towards a Radical Democratic Politics. London: Verso.

Leonardi, Paul M., and Stephen R. Barley. 2010. "What's Under Construction Here? Social Action, Materiality, and Power in Constructivist Studies of Technology and Organizing." The Academy of Management Annals 4 (1): 1-51.

Littau, Karin. 2016. "Translation and the Materialities of Communication.” Translation Studies 9 (1): $82-96$.

Longino, Helen. 1990. Science as Social Knowledge: Values and Objectivity in Scientific Inquiry. Princeton, NJ: Princeton University Press.

Lukes, Steven. 2005. Power: A Radical View. 2nd ed. Basingstoke: Palgrave Macmillan.

Lynch, Michael. 2008. "Ideas and Perspectives." In The Handbook of Science and Technology Studies, ed. by Edward J. Hackett, Olga Amsterdamska, Michael Lynch, and Judy Wajcman, 3rd ed., 9-11. Cambridge, MA: The MIT Press.

Moore, Gordon E. 1975. "Progress in Digital Integrated Electronics." IEDM Technical Digest 1975: 11-13.

Morozov, Evgeny. 2013. To Save Everything, Click Here: The Folly of Technological Solutionism. New York: Public Affairs.

Nicolini, Davide. 2009. "Zooming In and Out: Studying Practices by Switching Theoretical Lenses and Trailing Connections." Organization Studies 30 (12): 1391-1418.

2012. Practice Theory, Work, and Organization: An Introduction. Oxford: Oxford University Press. 
O’Brien, Sharon. 2012. “Translation as Human-Computer Interaction.” Translation Spaces 1 (1): 101-22.

O’Hagan, Minako. 2016. "Massively Open Translation: Unpacking the Relationship Between Technology and Translation in the 21st Century." International Journal of Communication 10: 929-46.

Olohan, Maeve. 2011. "Translators and Translation Technology: The Dance of Agency." Translation Studies 4 (3): 342-57.

Olohan, Maeve. Forthcoming 2017. "Knowing in Translation Practice: A Practice-Theoretical Perspective." Translation Spaces 6 (1).

Orlikowski, Wanda J., and Susan V. Scott. 2008. "Sociomateriality: Challenging the Separation of Technology, Work and Organization." The Academy of Management Annals 2 (1): 433-74.

Orr, Julian Edgerton. 1996. Talking about Machines: An Ethnography of a Modern Job. Ithaca, NY: Cornell University Press.

Pinch, Trevor J., and Wiebe E. Bijker. 1984. "The Social Construction of Facts and Artefacts: Or how the Sociology of Science and the Sociology of Technology might Benefit each other." Social Studies of Science 14 (3): 399-441.

Reckwitz, Andreas. 2002. "Toward a Theory of Social Practices: A Development in Culturalist Theorizing." European Journal of Social Theory 5 (2): 243-63.

Robinson, William I. 2012. "Global Capitalism Theory and the Emergence of Transnational Elites." Critical Sociology 38 (3): 349-63.

- 2004. A Theory of Global Capitalism: Production, Class, and State in a Transnational World. Baltimore: John Hopkins University Press.

Schatzki, Theodore R. 1996. Social Practices: A Wittgensteinian Approach to Human Activity and the Social. Cambridge: Cambridge University Press.

. 2001. "Introduction: Practice Theory." In The Practice Turn in Contemporary Theory, ed. by Theodore R. Schatzki, Karin Knorr-Cetina, and Eike von Savigny, 1-14. London: Routledge.

Shove, Elizabeth, Mika Pantzar, and Matt Watson. 2012. The Dynamics of Social Practice. London: Sage.

Sismondo, Sergio. 2010. An Introduction to Science and Technology Studies. 2nd ed. Chichester: John Wiley \& Sons.

Thorpe, Charles. 2008. "Political Theory in Science and Technology Studies." In The Handbook of Science and Technology Studies, ed. by Edward J. Hackett, Olga Amsterdamska, Michael Lynch, and Judy Wajcman, 3rd ed., 63-82. Cambridge, MA: The MIT Press.

van der Meer, Jaap. 2016. "The Future Does Not Need Translators." TAUS Blog. Accessed February 24, 2016. https://taus.net/blog/the-future-does-not-need-translators.

Warde, Alan. 2016. The Practice of Eating. Cambridge: Polity Press.

Wajcman, Judy. 2004. TechnoFeminism. Cambridge: Polity Press.

Winner, Langdon. 1983. "Technologies as Forms of Life.” In Epistemology, Methodology and the Social Sciences, ed. by Robert S. Cohen, and Marx W. Wartofsky, 249-263. Dordrecht: D. Reidel. Reprinted in Winner, Langdon (1986) The Whale and the Reactor: A Search for Limits in an Age of High Technology. Chicago: University of Chicago Press.

. 2001. "Where Technological Determinism Went." In Visions of STS: Counterpoints in Science, Technology, and Society Studies, ed. by Stephen H. Cutcliffe, and Carl Mitcham, 1118. Albany, NY: SUNY Press. 
. 2008. "Technological Determinism is Dead: Long Live Technological Determinism." In The Handbook of Science and Technology Studies, ed. by Edward J. Hackett, Olga Amsterdamska, Michael Lynch, and Judy Wajcman, 165-80. Cambridge, MA: The MIT Press. 